\title{
Ethnic differences in risk of hip fracture in Norway: a NOREPOS study
}

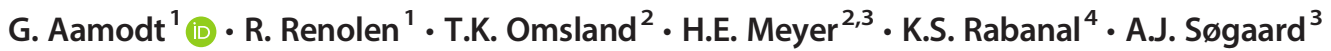

Received: 8 November 2019 / Accepted: 11 March 2020 / Published online: 7 April 2020

(C) The Author(s) 2020

\begin{abstract} individuals born in Norway. in risk of hip fracture between ethnic groups living in Norway. model risk of hip fracture as a function of region of birth. $0.1-0.3$ and $\mathrm{HR}=0.2,95 \%$ CI $0.2-0.4$ in men and women, respectively).

Keywords Country of birth $\cdot$ Epidemiology $\cdot$ Ethnicity $\cdot$ Hip fracture $\cdot$ Norway

NOREPOS (The NORwegian EPidemiologic Osteoporosis Studies) is a collaboration between epidemiologic osteoporosis studies, which are substudies within large population-based surveys in four districts of Norway (Tromsø, Nord-Trøndelag, Hordaland, Oslo). The NOREPOS Hip fracture Database (NORHip) includes all hospitalizations for hip fracture in Norway.
\end{abstract}

Summary Hip fracture is a major public health problem, and the incidence rates vary considerably between countries. Ethnic differences in bone mineral density have been identified as a factor to explain some of the geographical differences in rates of hip fracture. In this Norwegian register-based study, we found that all immigrant groups experienced lower risk of hip fracture than

Introduction Norway is among the countries with the highest incidence rates. The aim of this study was to investigate differences

Methods We linked individuals in the Norwegian Population and Housing Census conducted in 2001 and a database consisting of all hip fractures in Norway in the period 2001-2013. Residents $(n=1,392,949)$ between 50 and 89 years and born in nine different geographical regions of the world were examined, and we computed age-standardized incidence rates for the different geographic regions - denoted ethnic groups in the paper. Gender-stratified Cox regression analysis, adjusted for age, was used to

Results Age-standardized incidence rates of hip fracture varied considerably between regions of birth living in Norway, in both genders. All immigrant groups had lower risk of hip fracture compared to the Norwegian-born population. Immigrants from Central and Southeast Asia had the lowest risk of hip fracture when compared to individuals born in Norway $(\mathrm{HR}=0.2,95 \% \mathrm{CI}$

Conclusion Lower risk of hip fracture was found in all immigrant groups compared to the Norwegian-born majority population.

Electronic supplementary material The online version of this article (https://doi.org/10.1007/s00198-020-05390-4) contains supplementary material, which is available to authorized users.

G. Aamodt

geir.aamodt@nmbu.no

1 Department of Public Health Science, Faculty of Landscape and Society, Norwegian University of Life Sciences, Post box 5003, NMBU, 1432 Ås, Norway

2 Department of Community Medicine and Global Health, Institute of Health and Society, University of Oslo, Oslo, Norway

3 Department of Chronic Diseases and Ageing, Division of Mental and Physical Health, Norwegian Institute of Public Health, Oslo, Norway

4 Department of Public Health, Faculty of Health Sciences, University of Stavanger, Stavanger, Norway

\section{Introduction}

Hip fracture is a major public health problem, and the incidence rates vary considerably between countries [1-3]. The Norwegian population has one of the highest incidence rates of hip fracture in the world [1-3]. Studies of geographic distribution of hip fracture rates show that the highest rates are observed in Northern Europe and the USA, and the lowest in Latin America, Africa and Asia [1-3]. Ethnic differences in bone mineral density have been identified as a factor to explain some of the geographical differences in rates of both hip fracture and fractures in general [4].

Even though a decline in the incidence of hip fracture rates has been identified over the last 15-20 years in many Western societies, the total burden of hip fractures is expected to increase in the future because of an increasing number of elderly in the population [5].

Differences in incidence rates between ethnic groups within countries are less studied [4, 6, 7]. In Norway, $11 \%$ of the population in 2012 were first-generation immigrants 
(www.ssb.no/statbank), and this percentage is steadily increasing. The aim of the current study was to investigate the risk of hip fracture in individuals with foreign countries of birth living in Norway compared to individuals born in Norway.

\section{Materials and methods}

\section{Data sources}

The study population consisted of all Norwegian citizens 50 to 89 years who were included in the Population and Housing Census, conducted in 2001. We also included individuals who had immigrated to Norway during the period 1 January 2001 to 31 December 2013 and who were between 50 and 89 years 1 January 2001. The population at risk (50-89 years per 1 January 2001) was updated January 1 each year during 2001-2013 with information from the Population Registry.

The population data was linked to the NORHip database consisting of all hip fractures treated in Norwegian hospitals in the period 1994-2013. NORHip was established by the Norwegian Epidemiologic Osteoporosis Studies (NOREPOS) research collaboration and includes approximately 189,000 hip fractures [8]. In short, hip fractures were identified through standardised codes for diagnosis during hospitalisation. Information about all patients with a hip fracture diagnosis was extracted from the hospitals' patient administration systems, linked with a unique 11-digit personal identification number. All identifications correspond with the International Classification of Diseases, Ninth Revision (ICD9): 820-820.9 and Tenth Revision (ICD-10): S72.0-S72.2 [8]. More information may be found online: www.norepos.no/ documentation. The date of death was recorded for those who died during the study period.

\section{Observation time}

Total observation time for the study started 1 January 2001 (Population and Housing Census) or at arrival to Norway (immigration date). End of follow-up for each participant was hip fracture, emigration, death or the study's ending-point (31 December 2013), in that order of priority. Only individuals with their first hip fracture between 1 January 2001 and 31 December 2013 were included.

\section{Exposure variable}

We used region of birth as an approximation for ethnicity. The grouping of the country of birth was based on a previous publication with 15 regions [9]. Because of relatively few hip fractures among individuals from certain regions, we used only nine regions based on assumed geographic similarities: Norway, Western Europe, Eastern Europe (including former
Yugoslavia), Africa, Middle East, Indian subcontinent (including South Asia) and East Asia, North America, Central and South America, and Central and Southeast Asia (Supplementary Table S1). Individuals originating from countries in or near the Pacific Ocean were excluded due to few hip fractures within this group. The total population size was $1,392,949$ individuals and with $15,190,023$ person-years.

\section{Covariates}

Age was divided into four groups based on the individuals' age 1 January 2001: 50-59 years, 60-69 years, 70-79 years, and $80-89$ years.

\section{Statistical analyses}

We computed age-standardised incidence rates as the number of fractures divided by the number of years at risk of the first hip fracture using a direct standardisation method. The figures are reported as a number of fractures per 10,000 person-years. The Norwegian population represented in the dataset was used as a standard population, and we used 10-year age-strata for standardisation. Cox-regression was used to model the risk of hip fracture as a function of region of birth and age grouped into 5 -year categories. The model produced age-adjusted hazard ratios (HR) and corresponding 95\% confidence intervals for the risk of hip fracture in groups of regions of birth, compared to those born in Norway. We also conducted a sensitivity study where we fitted two additional models: (1) including age as a continuous variable and (2) including only individuals aged below 80 years. In separate models, we included interaction terms between age and region of birth. In these analyses, we reduced the ethnic groups to four: Norway, Europe, America and Asia/Africa. All analyses were stratified on gender. We used $\mathrm{R}$ version 3.6.1 to analyse the data and $p$ values less than 0.05 were considered as statistically significant.

\section{Ethics}

The present study and the linkage of data were approved by the Regional Committee for Medical and Health Research Ethics, The Norwegian Data Protection Authority, the Directorate of Health and Statistics Norway.

\section{Results}

A total of 97,186 hip fractures were identified: 29,096 in men and 68,090 in women. Mean age at fracture for participants $50-89$ years was 79.7 years among men and 82.2 years among women.

Table 1 lists the number of individuals, number of hip fractures, age-standardised incidence rates for the 
Table 1 Number of individuals aged 50-89 years old in 20012013, number of hip fractures, age-standardised incidence rates (IR) per 10,000 person-years and age-adjusted hazard ratio (HR) of hip fracture with $95 \%$ confidence interval $(\mathrm{CI})$ for the different countries of birth-stratified on gender

\begin{tabular}{lllllll}
\hline & $N$ & No. hip fractures & IR & $95 \%$ CI & HR & $95 \%$ CI \\
\hline Men & & & & & & \\
Norway & 627,420 & 28,551 & 41.8 & $(41.3-42.3)$ & 1 & (Reference) \\
Western Europe & 15,883 & 338 & 33.0 & $(29.1-36.9)$ & 0.8 & $(0.7-0.8)$ \\
Eastern Europe & 3112 & 58 & 22.4 & $(16.2-28.5)$ & 0.5 & $(0.4-0.7)$ \\
Africa & 1469 & 9 & 15.1 & $(0.6-29.7)$ & 0.3 & $(0.2-0.5)$ \\
Middle East & 1604 & 18 & 23.1 & $(9.0-37.3)$ & 0.5 & $(0.3-0.8)$ \\
Indian subcontinent and East Asia & 3270 & 36 & 21.7 & $(13.3-30.1)$ & 0.5 & $(0.3-0.7)$ \\
North America & 1872 & 73 & 29.7 & $(22.6-36.8)$ & 0.7 & $(0.5-0.9)$ \\
Central and South America & 892 & 7 & 45.3 & $(0.0-92.4)$ & 0.4 & $(0.2-0.8)$ \\
Central and Southeast Asia & 1283 & 6 & 7.7 & $(0.8-14.4)$ & 0.2 & $(0.1-0.3)$ \\
Women & & & & & & \\
Norway & 704,414 & 66,505 & 86.3 & $(85.7-87.0)$ & 1 & $($ Reference) \\
Western Europe & 18,585 & 1092 & 70.4 & $(66.1-74.8)$ & 0.8 & $(0.8-0.9)$ \\
Eastern Europe & 3533 & 110 & 48.6 & $(38.2-59.0)$ & 0.5 & $(0.5-0.7)$ \\
Africa & 815 & 27 & 50.3 & $(29.1-71.5)$ & 0.6 & $(0.4-0.8)$ \\
Middle East & 1128 & 18 & 22.3 & $(11.0-33.5)$ & 0.4 & $(0.2-0.6)$ \\
Indian subcontinent and East Asia & 2488 & 56 & 45.2 & $(31.7-58.7)$ & 0.5 & $(0.4-0.6)$ \\
North America & 2484 & 248 & 75.6 & $(65.8-85.3)$ & 0.9 & $(0.8-1.0)$ \\
Central and South America & 882 & 14 & 27.8 & $(12.2-43.3)$ & 0.3 & $(0.2-0.5)$ \\
Central and Southeast Asia & 1815 & 20 & 19.1 & $(9.1-29.1)$ & 0.2 & $(0.2-0.4)$ \\
\hline
\end{tabular}

different regions of birth and age-adjusted hazard ratios for hip fracture compared to individuals born in Norway. In Norwegian men, the incidence rate (IR) was 41.8 per 10,000 person-years (95\% CI 41.3-42.3), whereas IR for other groups ranged from 7.7 (95\% CI 0.8-14.4) in Central and Southeast Asia to 45.3 (95\% CI 0.0-92.4) per 10,000 person-years in Central and South America (Table 1). In Norwegian women, the incidence rate per 10,000 person-years was 86.3 (95\% CI 85.7-87.0), whereas IR in other groups of women ranged from 19.1 (95\% CI 9.1-29.1) in Central and Southeast Asia to 75.6 (95\% CI 65.8-85.3) per 10,000 person-years in North America (Table 1).

Among men, the age-adjusted hazard ratios revealed a significantly lower risk of hip fracture in all ethnic groups compared to men born in Norway. The lowest hazard ratio was observed in men born in Central and Southeast Asia compared to individuals born in Norway $(\mathrm{HR}=0.2$, 95\% CI 0.1-0.3) (Table 1). The risk of hip fracture was significantly lower among all groups of women born outside Norway compared to women born in Norway. As in men, the group with the lowest hazard ratio compared to individuals born in Norway was women born in Central and Southeast Asia $(\mathrm{HR}=0.2$, 95\% CI 0.2-0.4) (Table 1). This means that Norwegianborn individuals have 5 times higher risk of hip fractures compared to individuals born in these regions.

We found a significant interaction term between age and region of birth for both women $(p=0.006)$ and men $(p=$ 0.052 ). Hazard ratio in the different regions of birth and age categories differ and are shown in Supplementary Table S2. As an example, African/Asian men and women showed a lower risk of hip fracture for all age groups compared to
Norwegian men and women. This is also shown in Fig. 1, depicting incidence rates of hip fracture between age groups and regions of birth.

Results from sensitivity analysis are shown in Supplementary Table S3 and are approximately as those reported in Table 1.

\section{Discussion}

We found a statistically significant lower risk of hip fractures in all immigrant groups compared to Norwegian-born individuals, except for women born in North America.

Several studies have investigated the worldwide risk of hip fracture [1-3]. In both men and women, Northern and Central Europe are considered as high incidence countries; North America, Russia and Australia as regions of moderate risk; and countries in Latin America and Southeast Asia are considered as low-risk areas [3]. We found the same pattern in our study of immigrants from these regions.

Studies have also reported different incidence rates in ethnic groups within countries. In the UK, the USA and Sweden, comparable results as ours have been reported. Individuals from Africa, East Asia and the Indian subcontinent had a lower risk of hip fracture compared to individuals from Europe and North America [10,11]. As other researchers have reported, we found the lowest hip fracture risk among immigrants from countries in Central and Southeast Asia [7].

\section{Possible explanations}

One possible explanation for the lower hip fracture rates in immigrants compared to Norwegian-born, is the so-called 

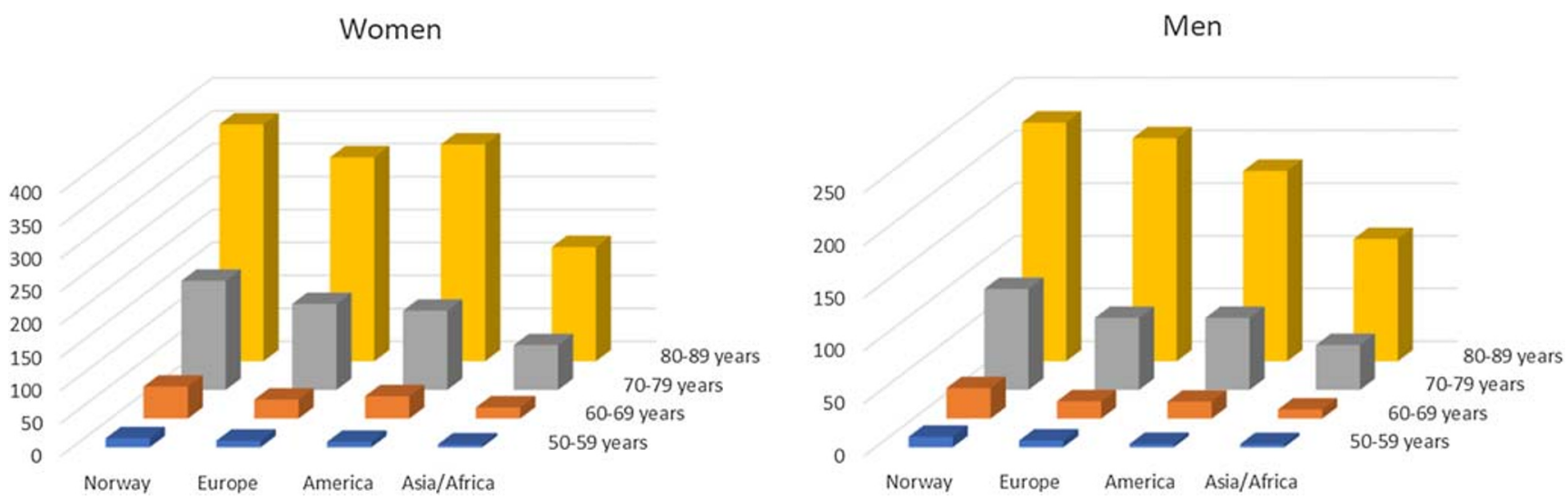

Fig. 1 Incidence rates (IR) of hip fracture for individuals 50-89 years dependent on age and country of birth

healthy migrant effect. That means there is a social selection involved in migration where the healthiest people decide and have the resources to migrate, which means that migrants are often healthier compared to their population of origin. This health selection in migration might explain parts of the health advantages in the immigrant population relative to the host population. Research also shows that immigrants' risk of adopting unhealthy behaviours increases with the duration of residence. In Norway, immigrants' risk of death became similar to that of the host population with increasing lengths of stay [12]. Thus, there must be other explanations than the "healthy migrant effect" to our findings.

We do not have data on hip fracture incidence from all the countries of origin and for all of the immigrant groups, and the patient registers in some of the countries are imperfect. It is also difficult to compare the incidence among immigrants in Norway with the incidence in their host countries because the age-distribution is different. The immigrant population in Norway is still relatively young and most persons born in other countries living in Norway, have not yet reached the peak age associated with high hip fracture incidence.

Ethnicity could play a role in the incidence and prevalence of osteoporosis and fractures - both thru genetic factors and thru risk factors such as smoking, nutrition, physical activity and body composition [7].

Low body weight or body mass index and high body stature are risk factors for hip fracture in both men and women $[13,14]$. In Norway, the prevalence of obesity is highest among immigrants from Pakistan and Turkey [15], whereas people from Northern Europe are in general taller than people from non-Western countries $[13,16]$.

Pakistanis living in Oslo had about the same bone mineral density (BMD) in distal and ultra-distal forearm as Norwegianborn individuals, despite the fact that Pakistani immigrants in Oslo had a high prevalence of vitamin D deficiency [17].

Smoking increases the risk of hip fracture [18]. Among women from 10 countries with high immigration to Norway [19], the proportion of smokers were lower than in the total population of Norway. However, the corresponding figure among men was the opposite.

Inactivity is another risk factor for hip fracture, and we know that all immigrant groups included in a Norwegian study reported less physical activity than the total Norwegian population [19].

Thus, body mass index, height and smoking among women could explain limited parts of the differences we have observed in the present study. Inactivity and smoking among men born outside Norway seem to work in the opposite direction. Complex interactions between lifestyle and socioeconomic variables, age and countries of birth might explain why the risk of hip fracture is so different between populations from different origins. The differences in risk of hip fracture between the immigrant groups and those born in Norway are substantial and it is likely that also genetic and epigenetic factors, could explain parts of these differences [7]. However, according to a study by Wallace et al. [20], the variability in incidence rates relates mainly to nongenetic factors.

\section{Strengths and limitations}

The strength of the study is the size of the population, the completeness of the registers covering the whole country and the quality of the hip fracture database. The study includes all residents living in Norway included in the Population and Housing Census in 2001, as well as individuals who immigrated to Norway during the study period. The NORHip database, containing all hip fractures in Norway sustained during the study period, has a high ascertainment [14], see www. norepos.no/documentation. However, several of the regions of birth, such as Central and South America and Central and Southeast Asia, had few individuals with hip fracture, resulting in wide confidence intervals.

We do not have data on other diseases among the participants in our study, which is a limitation. Although some immigrant groups have a higher risk of cardiovascular diseases 
compared to Norwegian-born [9], immigrants do not have higher total mortality compared to men and women born in Norway [12]. The lower risk of hip fractures in immigrants can thus not be explained by an early death.

Another limitation is the lack of information about the time of residence in Norway for the immigrants, which could have given some indication on whether the hip fracture differences were caused mainly by factors before migration (including genetics and early life exposure) or by factors after migration. Findings from Norway's neighbouring country of Sweden indicate that both factors may be correct. Among immigrants to Sweden, the risk of hip fractures increased with time since immigration, but the risk remained far lower than that for Swedish-born individuals of the same age [10].

We did not have information about recurring stays outside Norway during the study period. Individuals could also have experienced a hip fracture while staying outside Norway. The use of region of birth to indicate ethnicity is also a limitation as it gives large and heterogeneous ethnic groups.

Finally, there were few individuals among the oldest in some of the immigrant groups. Thus, some immigrants have contributed to fewer person-years in the age-group when fractures usually occur, compared to other groups. Although we have adjusted for age, this limitation could have influenced the results. However, our sensitivity analysis excluding persons older than 80 years of age, indicated this was not a serious problem.

Although not the purpose of this study, it would have been interesting to look at possible explanatory variables to understand differences in hip fracture risk among ethnic groups. To better understand the attributable fractions of the different explanatory variables, detailed information about all relevant variables should be included in future studies.

\section{Conclusion}

We found a lower risk of hip fracture among immigrants born in countries outside of Norway compared to individuals born in Norway. Both in men and women, we found the lowest fracture risk among immigrants from Central and Southeast Asia. Norwegian-born individuals had more than 5 times the risk of hip fractures compared to individuals born in these countries.

Acknowledgements Data from the Norwegian Patient Register has been used in this publication. The interpretation and reporting of these data are the sole responsibility of the authors, and no endorsement by the Norwegian Directorate of Health is intended nor should be inferred. Staff in the Norwegian Institute of Public Health and Statistics Norway is acknowledged for data collection, quality assurance and linkage to hip fracture data.

Funding Information Open Access funding provided by Norwegian University of Life Sciences.

\section{Compliance with ethical standards}

Conflict of interest Geir Aamodt, Rannveig Renolen, Tone K. Omsland, Haakon E. Meyer, Kjersti Stormark Rabanal and Anne Johanne Søgaard declare that they have no conflicts of interest.

Open Access This article is licensed under a Creative Commons Attribution-NonCommercial 4.0 International License, which permits any non-commercial use, sharing, adaptation, distribution and reproduction in any medium or format, as long as you give appropriate credit to the original author(s) and the source, provide a link to the Creative Commons licence, and indicate if changes were made. The images or other third party material in this article are included in the article's Creative Commons licence, unless indicated otherwise in a credit line to the material. If material is not included in the article's Creative Commons licence and your intended use is not permitted by statutory regulation or exceeds the permitted use, you will need to obtain permission directly from the copyright holder. To view a copy of this licence, visit http://creativecommons.org/licenses/by-nc/4.0/.

\section{References}

1. Cauley JA, Chalhoub D, Kassem AM, Fuleihan Gel H (2014) Geographic and ethnic disparities in osteoporotic fractures. Nat Rev Endocrinol 10(6):338-351. https://doi. org/10.1038/nrendo.2014.51

2. Dhanwal DK, Dennison EM, Harvey NC, Cooper C (2011) Epidemiology of hip fracture: Worldwide geographic variation. Indian J Orthop 45(1):15-22. https://doi.org/10.4103/0019-5413. 73656

3. Kanis JA, Oden A, McCloskey EV, Johansson H, Wahl DA, Cooper C (2012) A systematic review of hip fracture incidence and probability of fracture worldwide. Osteoporos Int 23(9): 2239-2256. https://doi.org/10.1007/s00198-012-1964-3

4. Shin MH, Zmuda JM, Barrett-Connor E, Sheu Y, Patrick AL, Leung PC, Kwok A, Kweon SS, Nam HS, Cauley JA (2014) Race/ethnic differences in associations between bone mineral density and fracture history in older men. Osteoporos Int 25(3):837845. https://doi.org/10.1007/s00198-013-2503-6

5. Omsland TK, Magnus JH (2014) Forecasting the burden of future postmenopausal hip fractures. Osteoporos Int 25(10):2493-2496. https://doi.org/10.1007/s00198-014-2781-7

6. Furugren L, Laflamme L (2007) Hip fractures among the elderly in a Swedish urban setting: different perspectives on the significance of country of birth. Scand J Public Health 35(1):11-16. https://doi. org/10.1080/14034940600733925

7. Pothiwala P, Evans EM (2002) Chapman-Novakofski KM (2006) Ethnic variation in risk for osteoporosis among women: a review of biological and behavioural factors. J Women's Health 15(6):709 719. https://doi.org/10.1089/jwh.2006.15.709

8. Sogaard AJ, Meyer HE, Emaus N, Grimnes G, Gjesdal CG, Forsmo S, Schei B, Tell GS (2014) Cohort profile: Norwegian Epidemiologic Osteoporosis Studies (NOREPOS). Scand J Public Health 42(8):804-813. https://doi.org/10.1177/1403494814551858

9. Rabanal KS, Selmer RM, Igland J, Tell GS, Meyer HE (2015) Ethnic inequalities in acute myocardial infarction and stroke rates in Norway 1994-2009: a nationwide cohort study (CVDNOR). BMC Public Health 15:1073. https://doi.org/10.1186/s12889-0152412-z

10. Johansson H, Oden A, Lorentzon M, McCloskey E, Kanis JA, Harvey NC, Karlsson MK, Mellstrom D (2015) Is the Swedish 
FRAX model appropriate for Swedish immigrants? Osteoporos Int 26(11):2617-2622. https://doi.org/10.1007/s00198-015-3180-4

11. Hippisley-Cox J, Coupland C (2012) Derivation and validation of updated QFracture algorithm to predict risk of osteoporotic fracture in primary care in the United Kingdom: prospective open cohort study. BMJ (Clinical research ed) 344:e3427. https://doi.org/10. 1136/bmj.e3427

12. Syse A, Strand BH, Naess O, Steingrímsdóttir ÓA, Kumar BN (2016) Differences in all-cause mortality: A comparison between immigrants and the host population in Norway 1990-2012. Demogr Res 34(22):615-656

13. Meyer HE, Falch JA, O’Neill T, Tverdal A, Varlow J (1995) Height and body mass index in Oslo, Norway, compared to other regions of Europe: do they explain differences in the incidence of hip fracture? European Vertebral Osteoporosis Study Group. Bone 17(4):347-350

14. Sogaard AJ, Holvik K, Omsland TK, Tell GS, Dahl C, Schei B, Meyer HE (2016) Age and sex differences in body mass index as a predictor of hip fracture: A NOREPOS Study. Am J Epidemiol 184(7):510-519. https://doi.org/10.1093/aje/kww011

15. Kumar BN, Selmer R, Lindman AS, Tverdal A, Falster K, Meyer HE (2009) Ethnic differences in SCORE cardiovascular risk in Oslo, Norway. Eur J Cardiovasc Prev Rehabil 16(2):229-234. https://doi.org/10.1097/HJR.0b013e3283294b07

16. Robinson MR, Hemani G, Medina-Gomez C, Mezzavilla M, Esko T, Shakhbazov K, Powell JE, Vinkhuyzen A, Berndt SI, Gustafsson S, Justice AE, Kahali B, Locke AE, Pers TH, Vedantam S, Wood AR, van Rheenen W, Andreassen OA, Gasparini P, Metspalu A,
Berg LH, Veldink JH, Rivadeneira F, Werge TM, Abecasis GR, Boomsma DI, Chasman DI, de Geus EJ, Frayling TM, Hirschhorn JN, Hottenga JJ, Ingelsson E, Loos RJ, Magnusson PK, Martin NG, Montgomery GW, North KE, Pedersen NL, Spector TD, Speliotes EK, Goddard ME, Yang J, Visscher PM (2015) Population genetic differentiation of height and body mass index across Europe. Nat Genet 47(11):1357-1362. https://doi.org/ 10.1038/ng.3401

17. Alver K, Meyer HE, Falch JA, Sogaard AJ (2005) Bone mineral density in ethnic Norwegians and Pakistani immigrants living in Oslo-The Oslo Health Study. Osteoporos Int 16(6):623-630. https://doi.org/10.1007/s00198-004-1722-2

18. Hoidrup S, Prescott E, Sorensen TI, Gottschau A, Lauritzen JB, Schroll M, Gronbaek M (2000) Tobacco smoking and risk of hip fracture in men and women. Int J Epidemiol 29(2):253-259

19. Blom S (2008) Innvandrerers helse 2005/2006, vol 35. Statistics Norway, Kongsvinger

20. Wallace IJ, Botigue LR, Lin M, Smaers JB, Henn BM, Grine FE (2016) Worldwide variation in hip fracture incidence weakly aligns with genetic divergence between populations. Osteoporos Int 27(9): 2867-2872. https://doi.org/10.1007/s00198-016-3591-x

Publisher's note Springer Nature remains neutral with regard to jurisdictional claims in published maps and institutional affiliations. 